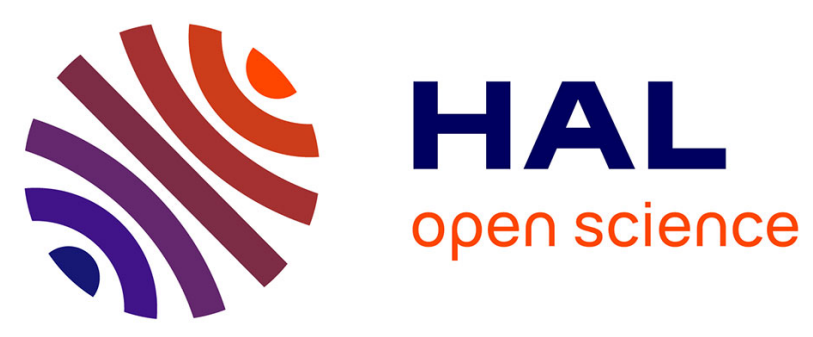

\title{
Developing a tool to assess trainees during crisis management training for major risks
}

Dimitri Lapierre, Aurélia Bony-Dandrieux, Florian Tena-Chollet, Gilles Dusserre, Jérôme Tixier, Karine Weiss

\section{- To cite this version:}

Dimitri Lapierre, Aurélia Bony-Dandrieux, Florian Tena-Chollet, Gilles Dusserre, Jérôme Tixier, et al.. Developing a tool to assess trainees during crisis management training for major risks. Luca Podofillini, Bruno Sudret, Bozidar Stojadinovic, Enrico Zio and Wolfgang Kröger. Safety and Reliability of Complex Engineered Systems, 26, CRC Press, pp.195-202, 2015, ESREL 2015, 9781315648415. 10.1201/b19094-30 . hal-01534534

\section{HAL Id: hal-01534534 \\ https://hal.science/hal-01534534}

Submitted on 7 Jun 2017

HAL is a multi-disciplinary open access archive for the deposit and dissemination of scientific research documents, whether they are published or not. The documents may come from teaching and research institutions in France or abroad, or from public or private research centers.
L'archive ouverte pluridisciplinaire HAL, est destinée au dépôt et à la diffusion de documents scientifiques de niveau recherche, publiés ou non, émanant des établissements d'enseignement et de recherche français ou étrangers, des laboratoires publics ou privés. 


\title{
Developing a tool to assess trainees during crisis management training
}

\section{for major risks}

\author{
D. Lapierre, A. Bony-Dandrieux, F. Tena-Chollet, G. Dusserre \& J. Tixier \\ Ecole des mines d'Alès, 6 avenue de Clavières, F-30 100 Alès, France
}

K. Weiss

Université de Nîmes, Rue du Docteur Georges Salan, F-30 000 Nîmes, France

\begin{abstract}
Often based on simulation exercises, crisis management training helps prepare decision-makers to manage crises better. However, this training has definite limits in terms of trainee assessment and the feedback given during the debriefing phase. This paper presents a method for better organising the assessment of trainees involved in a real time crisis management training exercises and for giving them feedback during the debriefing phase. The approach presented is based on creating a typology of training objectives in order to organise the assessment. The assessment includes expected outcomes techniques as well as the human and organisational factors that can be observed within a group. The assessment tools developed were then experimented within crisis management exercises completed with trainees. Beyond the basic results, these tools helped redefine the basic roles played by observers and trainers during training exercises.
\end{abstract}

\section{INTRODUCTION}

\subsection{The crisis unit}

The crisis management team (often called the 'crisis unit'), works in a dynamic environment under suboptimal conditions. Its objective is to implement measures based on anticipation, caution, and intervention to provide the appropriate response for managing a crisis (Lachtar, 2012). A crisis erupts abruptly, and is complex for decision-makers to manage, even more so during the acute phase, which conflates time pressure, uncertainty, and decisions taken under urgent conditions. This acute phase, which follows the event triggering the crisis, features stressful changes in situations and the need for rapid coordination of those involved so as to provide an initial operational response (Dautun, 2007).

\subsection{Defining the crisis and its 'symptoms'}

A crisis is thus experienced as a moment of transition that could result in a definitive break between two states. It requires major decisions to be taken under urgent conditions and based on an assessment of the real state of things (Crocq et al., 2009; Heiderich, 2010; Pearson et al., 2007). A crisis can totally or partially affect the organisation handling the crisis, which may have to pay a heavy tribute in terms of human lives, equipment, money, or its reputation) (Coombs, 2010).

Decision-making is therefore complex during crisis management, which is exacerbated by the unexpected nature of the event and its detection. A crisis is characterised by the following properties:

- Uncertainty: there may be multiple or vague sources of information, and the information may be lacking or ambiguous (Crichton, 2001; Lagadec, 2012; Pearson \& Clair, 1998) or massive and contradictory (Yammarino et al., 2010). However, the confusion reigning requires a rapid response based on a decision that must be taken fast (Sayegh et al., 2004),

- Urgency: whether the 'kinetics' are slow or fast, decision-makers must react very quickly and with major time pressure (Crichton, 2001; Hannah et al., 2009; Lagadec, 1991; Pearson \& Clear, 1998),

- Significant short-term losses: Minimising these losses is the principal objective of crisis management (1997; Pearson \& Clear, 1998),

- A loss of control of the situation: events spin out of control, and reality falls apart (Heiderich, 2010)

- High levels of stress (Crichton, 2001; Crocq et al., 2009; Kowalski-Trakofler \& Vaught, 2003) 
These properties alter the basic activities that affect the crisis management organisation, particularly at the very beginning of the crisis management process. In an extremely complex and dynamic environment, it must do its utmost to verify the sources of information, describe in detail the current problem (from its nature to the actions to be carried out), identify the people or organisations with knowledge of the event, and find a solution and implement it while controlling its effects (Crocq et al., 2009; Roux-Dufort, 2007). The evolution of the crisis destabilises the organisation managing it, which must cope with the changing situation.

\subsection{The need for crisis management training}

Given the complexity of a crisis, managers must be ready for this kind of situation: they must prepare themselves to be surprised, while learning to be creative in unfamiliar situations (Lagadec, 2012). Taking training courses, and in particular completing crisis management exercises, is one way to achieve this objective. On the one hand, crisis management training objectives are established to test out the documentation, plans and procedures for handling the crisis (how operational these tools are in general). On the other hand, crisis management stakeholders should also acquire experience and improve their level of expertise and all their skills linked to teamwork (Crichton, 2001; Heiderich, 2010; Sayegh et al, 2004; Gaultier-Gaillard et al., 2012).

Crisis manager trainers must therefore include training activities that focus on using skills linked to teamwork in stressful situations. Crisis management staff must indeed be able to use this set of skills naturally in order to limit dysfunctions (Crichton \& Flin, 2004). During a crisis management training session, trainees must use this set of skills progressively to react to the specific events in the exercise scenario, while their evaluators assess how these skills are used throughout the exercise (Shapiro et al., 2008). At the end of the exercise, the feedback given to trainees during the debriefing phase is crucial. It is a vital part of the learning process, because it will enable them to understand how they performed (Fanning \& Gaba, 2007; Salas et al, 2009; Shinnick et al, 2011). Whereas it is commonly acknowledged today that crisis management training is indispensable for decision-makers, this paper shows that there is, however, no operational tool for real time assessment of a strategic crisis unit specialising in major risks.

Thus, by using an approach based on crisis management training exercises, this paper aims to present an assessment tool that takes account of technical skills as well as human and organisational factors during crisis management exercises (simulations).

This paper is organised in three parts. Part 1 establishes the state of the art concerning dysfunctions encountered by a crisis unit managing an emergency. It describes different training courses that prepare crisis management decision-makers to cope, in terms of technical as well as non-technical skills. The state of the art of current assessment tools is also presented, highlighting in particular how difficult it is to adapt them to the crisis management context. The next part presents the methodology used to create a tool that is operational during crisis management training courses. Finally, the initial results of our experimentation using this methodology during crisis simulation exercises are presented and discussed.

\section{REVIEW}

\subsection{Dysfunctions identified in crisis units}

Beyond the difficulties linked to technological equipment and organisation, in crisis management, questions relating to group behaviour crop up repeatedly. Lagadec (1991) highlights that the principal failures in exceptional circumstances are related to group behaviour.

Serious dysfunctions can occur within the crisis unit (Table 1). We have grouped them together in several categories: dysfunctions linked to problems of communication, to understanding the situation, to managing emotions and stress, as well as to organisational issues.

Table 1. Organisational dysfunctions identified in a crisis unit

\begin{tabular}{|c|c|}
\hline \multicolumn{2}{|l|}{ Dysfunctions linked to communication } \\
\hline Poor information sharing & King et al., 2008 \\
\hline Communication not clear & Crichton \& Flin, 2004 \\
\hline $\begin{array}{l}\text { Loss of information, only basic in- } \\
\text { formation retained }\end{array}$ & $\begin{array}{l}\text { Kowalski-Trakofler } \\
\text { \&Vaught, } 2003\end{array}$ \\
\hline \multicolumn{2}{|l|}{ Dysfunctions linked to the situation } \\
\hline $\begin{array}{l}\text { Hard to obtain a common operational } \\
\text { image }\end{array}$ & n et al., 2013 \\
\hline Meaning collapses (cf. sensemaking) & $\mathrm{We}$ \\
\hline $\begin{array}{l}\text { Poor representation of the risk and } \\
\text { deviance becomes the norm }\end{array}$ & in, 1996 \\
\hline Negati & 2012 \\
\hline $\begin{array}{l}\text { Assessment of situation unsuitable or } \\
\text { wrong }\end{array}$ & $\begin{array}{l}\text { Crichton \& Flin, 2004; } \\
\text { Orasanu, } 2010\end{array}$ \\
\hline \multicolumn{2}{|l|}{ Dysfunctions linked to stress } \\
\hline $\begin{array}{l}\text { Denial, incapacity to act, feeling of } \\
\text { invulnerability }\end{array}$ & Kouabenan et al., 2006 \\
\hline Shock and awe & $\mathrm{t}$ al., 2009 \\
\hline Disorientation of unit members & Heiderich, 2010 \\
\hline
\end{tabular}


Decreased caution and memory ca- Kontogiannis \& Kospacities

siavelou, 1999

Organisational dysfunctions

Collapse of coordination measures

Weick, 1995; Lagadec, 2012

Poor division of tasks, leadership un- Kanki, 2010 dermined

Blindly following procedures or applying them poorly

Internal tension, conflicts

Crichton \& Flin, 2004

van Vliet \& van

Amelsfoort, 2008

The identification of these dysfunctions confirms that many of them are linked to technical issues, but also that many others are related to human factors and non-technical skills. Whereas the principal risky activities (military, medical, aeronautics, and aerospace) have managed to adapt their training to include technical and non-technical skills, crisis management training for major risks has lagged behind. Today, it is vital to take account of human and organisational factors more adequately in this kind of crisis management training.

\subsection{Current training courses that take account of non-technical skills}

To respond to this demand, various training strategies focus on teamwork, human factors, and how a group can adapt to a changing environment under suboptimal conditions. The following approaches are the best adapted to these criteria: CRM (Crew Resource Management), EBAT (Event Based Approach to Training), CTT (Critical Thinking Training), CT (Cross Training), SET (Stress Exposure Training), team adaptation and coordination training, team leader training, and team self-correction (Cohen et al., 1998; Day et al., 2004; Fowlkes \& Burke, 2005; Kanki et al., 2010; Kosarzycki et al., 2002; O'Connor \& Flin, 2003; Rosen et al., 2010; Salas \& Cannon-Bowers, 2001; Wollert \& Driskell, 2011).

We may observe that these various group-training activities tend to be organised around experiencebased learning, which relies on exercises requiring the use of an entire set of skills. The importance of functional and simulation-based exercises is growing: they enable people to learn while using and improving the skills they already have (Kosarzycki et al., 2002; Raybourn et al., 2005). Learning is maximized by engaging in a dynamic behavioural process, and being fully plunged into a contextualised environment, which is as realistic as possible (Power et al., 2013; Salas et al., 2009). Because of the advantages of these functional exercises, we used them to try to assess the trainees, while encouraging them to make use of technical and non-technical skills as they engaged in the crisis management scenarios.

\subsection{Assessment that is hard to organise...}

No matter what framework is used for crisis management training exercises, the training objectives must be clearly identified. No valid exercise or assessment of trainees can take place if the trainers do not first identify the training objectives precisely (Dubiau, 2007). Therefore, to be able to assess the trainees, a method of assessment must be set up that is based on the clear identification of the training objectives.

A training objective is not a learning activity; rather the trainers must ask themselves the question 'what must the learners be capable of doing?' (Anderson et al., 2001). The identification of the training objectives and the criteria for achieving them provide the basis for the subsequent assessment carried out by the trainers.

However, even if the assessment criteria have been defined, the trainers must also be able to assess them during the training session. The direct observation of the trainees during the training sessions is the most widely used method for collecting information about a group. This information must be organised, and the assessors must also be trained in how to use the various media for collecting data (Dimock \& Kass, 2010). The assessment is thus based on direct observation, as much as possible, contrary to virtual simulations in which what trainees do is directly recorded by a computer (Caird-Daley et al., 2007). Of particular importance is the fact that observationbased assessment can evaluate the group dynamics leading up to the decision taken. These reactions can only be detected by human observation (Rosen et al., 2010). Therefore, the assessment of a group of trainees on a crisis unit should utilise two complementary approaches: the non-technical skills can be assessed by human observers, while the technical skills can be observed by humans and also by a computer based tool.

\subsection{Advantages linked to observation techniques}

Characterising team processes and performances requires above all analysis of them. (Entin \& Entin, 2001). Yet the technique used for direct observation has many advantages that are worth describing. Direct observation enables evaluators to focus more on the non-technical skills (or behavioural markers) enacted within a group, such as communication, leadership, and the capacity of leaders to orient their team, as well as on the key skills of an organisation (Kosarzycki et al., 2002). It also enables them to focus on team processes, and the strategies employed by the group to take decisions (Annett et al., 2000). 
This direct observation of behaviour is therefore an indispensable complement to the actions performed (Rosen et al., 2010). Only an observer can detect attitudes linked to specific events or behaviour caused by other members of the group, (Fowlkes \& Burke, 2005). The same is true of knowing how to identify whether or not skills and behaviour are related to a task to perform or to improving the coordination of team members (Burke, 2005). A team of trained managers that is resolving problems must be analysed according to its ability to adapt to the behaviour of other members as well as in terms of the group's cognitive, affective, and motivational resources (Marks et al., 2001; Shanahan et al., 2007). The assessment of the trainees we propose in this paper takes into account assessment by trainers and direct observation of trainees. A third assessment is performed by trainees through a selfevaluation questionnaire.

\subsection{What tools can be used to observe a crisis unit?}

We also looked for existing assessment tools that could be used to assess both the technical and the non-technical skills of a group of trainees. Our study was performed in fields in which organisations work in emergency situations, and enabled us to identify similar fields in which crisis management is used-medicine, military, aeronautics, and aerospace (Helmreich \& Foushee, 2010). Based on this observation, we looked for assessment tools used in training courses in these different fields. We identified 39 tools for assessing trainees during a training session. Comparing them enabled us to differentiate them on the basis of the following criteria:

- The media: five kinds of media used for assessment were identified (checklists, grids, questionnaires, interviews, and software).

- The time period: assessment can be carried out over different time periods (before, during, after, and comparatively)

- The scale: the assessment tool can be used at the scale of the individual or the group.

- The content: the content covered by these assessment tools varies. It may concern the expected technological outcomes specific to the crisis management exercise, the technical and non-technical skills of a group, the content of a training course, the experience of the members in a group, and their needs or feelings.

Our comparison showed that for a real time assessment at the group scale, covering technical and non-technical skills, only 3 tools satisfy all of these criteria: TARGETs (Fowlkes et al., 1994; Fowlkes \& Burke, 2005), LOSA (ICAO, 2002; Thomas et al., 2004), TEAM (Cooper et al., 2010). However, their principal drawbacks are that they are effective especially for small groups (6 people maximum) in a small space. For example, in an airplane cockpit, the flight team is made up of three people (on average), who have their predefined seats and a limited range of movement. The situation is similar for a medical team during an operation. On the contrary, a crisis unit is organised and has interactions in ways that are much more mobile and in contact with the outside world. It must also know how to go beyond the narrow framework of procedures when there is an emergency situation.

In addition, the design of these tools, which are specific for each exercise, is costly in terms of time, and also require input from experts to identify the expected outcomes. Finally, the expected outcomes entered into these tools are generally coded for each event in the exercise, which gives them limited flexibility. We may thus observe that the tools we identified are hard to adapt to crisis management training, so another method must be created that will enable us to improve them.

\section{METHOD}

Our methodological approach to creating a real-time assessment tool for a crisis unit made up of trainees involves several steps:

- First, creating a typology of objectives and expectations concerning a strategic crisis in the area of major risks, i.e. integrating technical and non-technical skills (human factors). This typology of training objectives will enable the assessment of the trainees to be better organised,

- Second, monitoring a group in real time: the assessment is performed using a specific observation grid, questionnaire (non-technical and technical skills, group dynamics, behaviour), which is correlated with both the scenario and the trainees' needs,

- Third, organising the data collected using the assessment tools in order to analyse them, use them as a training aid for the exercise, and present them during the debriefing phase at the end of the exercise.

To create the tool for assessing in real time a crisis unit made up of trainees during a crisis management 
training exercise, the first step was to create a learning base. This learning base involves the creation of a typology of training objectives that we could incorporate into our training sessions. This learning base is indispensable, because the training is based on the precise identification of training objectives. It was therefore necessary to create a typology of objectives combining both the technical skills and the human and organisational factors that apply to a crisis unit.

This typology of training objectives will:

- Help construct and determine the content of the exercise scenario

- Structure the assessment of the trainees around precise points to be achieved

- Serve as a basis for designing the observation and assessment tools

Based on crisis management plans for major risks intended for decision-makers (Plan Communal de Sauvegarde, Plan Particulier d'Intervention, Plan d'Organisation Interne, ORSEC procedure), and typologies of the missions of a strategic crisis unit (Tena-Chollet, 2012) or the skills that an organisation needs to have (Kosarzycki et al., 2002; Salas and Cannon-Bowers, 2001), 16 missions were identified. From these 16 missions, 68 objectives to be achieved were determined, divided into three levels of difficulty (beginner, intermediate, expert).

Three broad categories of training objectives were distinguished when creating this typology. The three broad categories chosen are:

- The carrying out of the strategic crisis response: this category of training objectives is linked to missions of hazard assessment, determining issues affected, anticipating issues threatened, and managing the means of intervention and backup (Figure 1)

- The operation of the crisis unit: this second category concerns factors specific to the organisation of the crisis unit and to human factors. It therefore includes training objectives related to activating the crisis unit, identifying human resources within the team, organising and managing internal communication, steering and managing the crisis unit, maintaining a common vision of the situation, coordinating teamwork, and managing emotions.

- The operation of crisis communication both inside and outside the crisis unit: this third category includes media issues, with the drawing up of a press re- lease and the management of media information, communication with the general public and the population involved, communication with the authorities, and lastly communication with teams in the field.

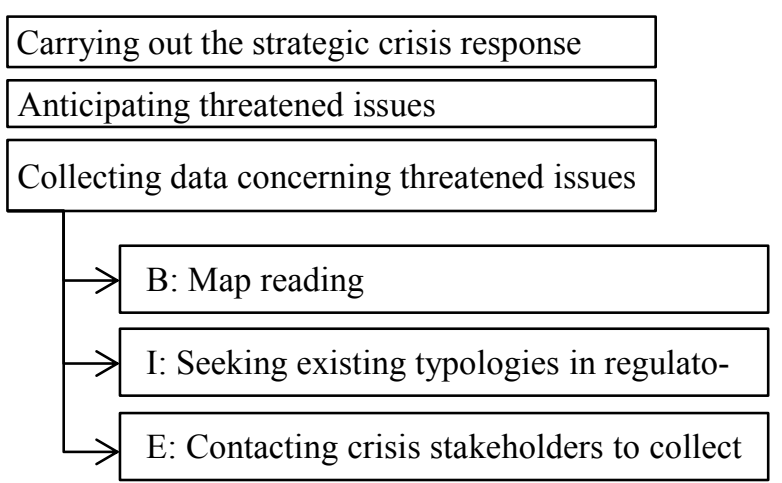

Figure 1. From the typology of training objectives

For example, among the various missions connected with the first broad category of training objectives 'carrying out the strategic crisis response', one of the decision-makers' missions is to anticipate the threatened issues in the area concerned. If we seek to assess the way in which the crisis unit will collect data regarding threatened issues, we highlight three ways to collect this information: 1) map reading for beginner-level trainees, 2) seeking existing typologies of issues in regulatory documents for intermediate-level trainees, and 3) directly contacting specific crisis stakeholders for expert-level trainees. Expectations for higher-level trainees include those required for the lower levels.

Based on these 68 training objectives, a distinction was made between the training objectives common to any crisis management exercise and those specific to the trainees concerned. 22 training objectives can be assessed whatever the exercise, for example those connected with assessing the phenomenon, characterising issues, steering and managing the crisis unit, coordination, and decision-making. The other 46 training objectives are variable, linked to the level of the trainees, their experience, the choice of events included in the exercise, and the number of observers and assessors available on the day of the exercise. For instance, training objectives connected with media management can only be assessed if media pressure is incorporated into the exercise on that day.

Once the training objectives have been identified for the exercise, a recapitulative table of the training objectives is generated. It features various indicators for the assessor, such as the name of the crisis subunit that must achieve the training objective, at what point in the scenario it should become involved, and which group will assess it. Let us consider a simula- 
tion in which the trainees (in the situation room) have to manage a crisis steered by a group of facilitators (in a separate facilitation room).

The assessment of the training objectives can then be carried out by two different groups. Objectives related to human factors and the internal organisation of the crisis unit can only be observed whereas others can only be assessed through exchanges between facilitators and trainees during the simulation.

On the one hand, the observers, in the simulation room, assess the trainees using a behavioural markers approach and other directly observable indicators (group dynamics, leadership, coordination of team members, teamwork, and organisation of the group) by means of a checklist. On the other hand, the facilitators, in the facilitation room, assess the fulfilment of training objectives from the responses formulated by the trainees concerning the scenario, and aggregate various assessment indicators, such as how precise their response is, the time taken to formulate a response, and whether the right person was contacted regarding a request.

Finally, a third assessment is carried out directly by the trainees themselves using a post-exercise selfassessment questionnaire. The trainees, in the simulation room, receive various stimuli in function of the exercise scenario. These prompts result in actions and reactions. Training objectives can thus be directly assessed by means of messages in the exercise scenario where the facilitator concerned fills in an assessment grid specific to the training objectives linked to his/her role. In the event of non-fulfilment of training objectives, facilitators can insert new messages asking trainees to fulfil the objective concerned.

The process is identical for the observers: whenever a training objective is not fulfilled/achieved by the group of trainees, the observers fill in grids associated with the training objectives, which generate graphical representations highlighting the group's difficulties and strengths. In this case, certain facilitators (through the roles they play) can intervene during the course of the exercise by inserting messages into the scenario in real time. The facilitators who can make these prompts in the exercise scenario in real time are specified in advance.

Finally, the training objectives related to cognitive processes (feelings, justification of a decision) are assessed by the trainees themselves by means of the post-exercise self-assessment questionnaire.

\section{RESULTS}

Once the typology of training objectives for crisis management training exercises had been drawn up, the assessment tools for observers and facilitators could be created (Figure 2).

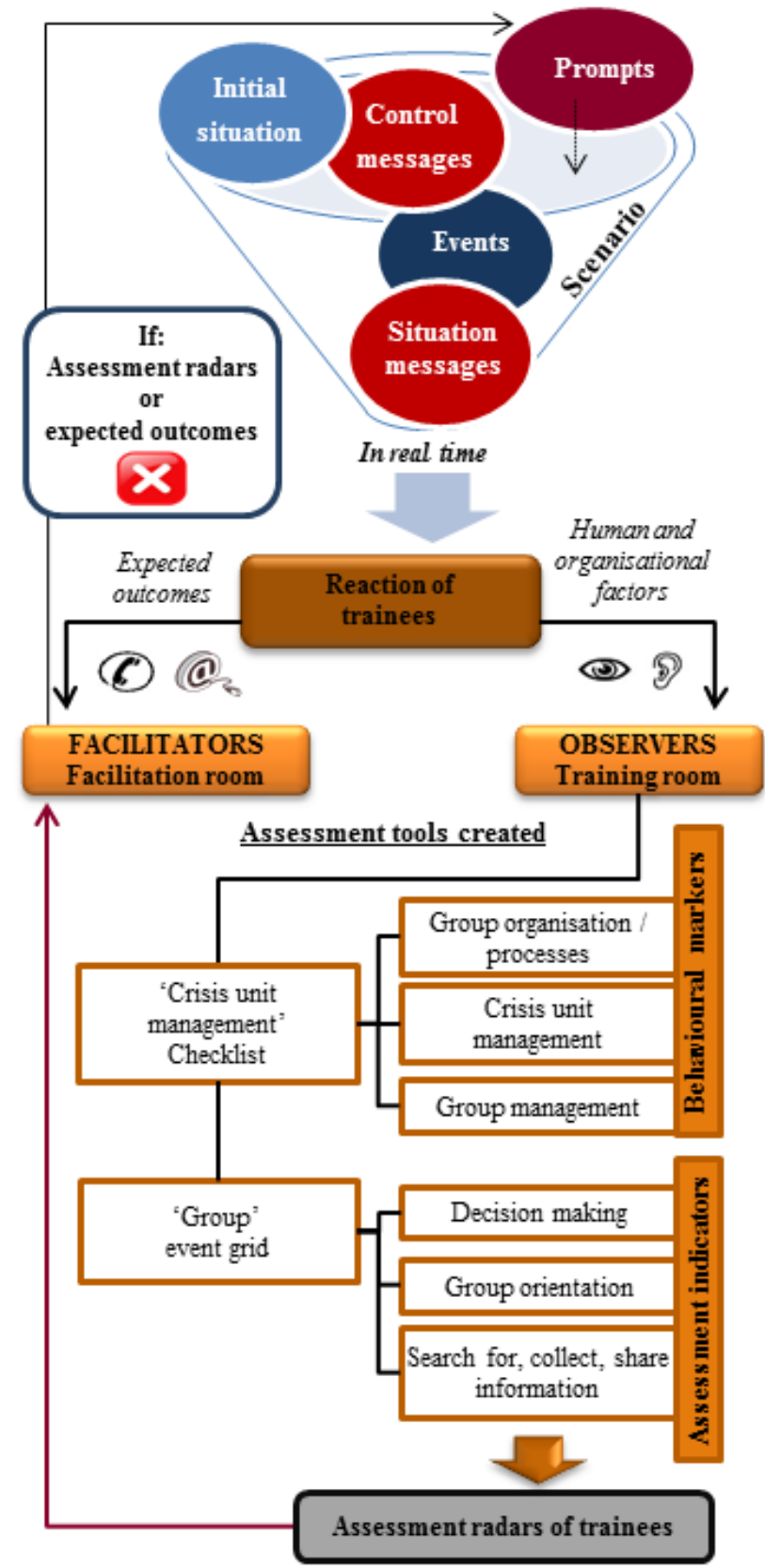

Figure 2. Assessment tool for a crisis unit made up of trainees and facilitators during a crisis management training exercise.

First, the training objectives assessed directly by observers in the room are linked to the key skills of a crisis management organisation. The behaviour checklist filled in by one observer is used to identify how the group organises itself to deal with the crisis, the leadership involved, the sharing of information, coordination, the way decisions are taken. The checklist, completed in real time by the observer, gives the results of the training room observations to inform facilitators about the trainees' reactions during the exercise.

A second observer, also in the same room as the trainees, fills in an event grid. This observer records the orientations chosen by the group throughout the exercise, the points that blocked the group, and for 
example indicates to the facilitators any trainees who are not very much involved. In addition to the results obtained by the grid, the innovative feature comes from the fact that those results are aggregated so that the facilitators can make a simple interpretation of the data they receive during the exercise. In this way, when the group of trainees goes the wrong way, for example, or does not achieve the expected outcomes, messages are generated for the facilitators to request or encourage them to reconsider a problem during the exercise.

This dynamic assessment approach thus modifies the observers' role. They become an actor in the exercise, in which their observations influence the series of messages. In addition to its ability to assess the group of trainees in real time, it also makes the training process richer and more flexible in function of the trainees' behaviour and reactions. There is the same extension of roles for the facilitators. They too, in the event of training objectives not being achieved at different points in the exercise, can insert request messages into the initial exercise scenario.

Whereas previous training courses could only provide an assessment of what had been achieved and the areas to be improved at the end of the exercise, this approach is favourable to learning throughout the training process. Moreover, the data collected and aggregated during the exercise can be used as points of discussion in the post-exercise debriefing phase.

\section{CONCLUSION}

Developing this method enabled us to finalise a set of tools for assessing a group of trainees in a crisis management training exercise. The method is to be adopted for training because it has several advantages: the typology of training objectives built is adapted for various crisis units (communal, prefectural, rescue, industrial) in the field of major risks. In addition, this method enables the assessment of a 1015 people group in real time. It is more flexible in practice because the observation tools are based on the approach of behavioural markers, therefore reproducible on different exercises. Then the results of grids generate recommendations for debriefing and help for the analysis at the restitution phase between trainers and trainees. Tested in crisis management simulation exercises with trainees, the assessment tools provided various types of results. Certain criteria such as those related to the organisation of the exercise group can be monitored and assessed on a continuous basis. Other criteria related to specific objectives, such as learning to structure a situation point, provide a finer assessment, but one that ap- plies to a more limited period of time. These tools were tested in the framework of crisis management training exercises with different trainee profiles (from beginner to expert) and were able to adapt to these different profiles. Now that the assessment tools are operational, the next issue is to structure the aggregation of the data collected during the exercise. Transmitting the data to the trainers in real time during the exercise involves setting up an intuitive system that does not require excessive cognitive resources in order to enable trainers to dynamically facilitate the exercise and lead to the achievement of training objectives.

\section{REFERENCES}

Anderson, L.W., Krathwohl, D.R., Airasian, P.W., Cruikshank, K.A., Mayer, R.E., Pintrich, P.R., Raths, J., \& Wittrock, M.C. 2001. A taxonomy for learning, teaching, and assessing: A revision of Bloom's Taxonomy of Educational Objectives. New York: Longman.

Annett, J., Cunningham, D. \& Mathias-Jones, P. 2000. A method for measuring team skills. Ergonomics, vol. 43, no. 8, pp. 1076-1094.

Burke, C.S. 2005. Team Task Analysis. In N. Stanton, A. Hedge, K. Brookhuis., E. Salas \& H. Hendrick (eds), Handbook of Human Factors and Ergonomics Methods. CRC Press, $681 \mathrm{p}$.

Caird-Daley, A. \& Harris, D., 2007. Training decision making using serious game. Human Factors Integration Defense Technology Centre, HFIDTC/2/WP4.6.1/1, 71 p.

Coombs, W.T. 2010. Parameters for crisis communication, pp.17-53. In W.T. Coombs \& S.H. Holladay (eds), The handbook of crisis communication. Wiley-Blackwell, $767 \mathrm{p}$.

Cooper, S., Cant, R., Porter, J., Sellick, K., Somers, G., Kinsman, L. \& Nestel, D. 2010. Rating medical emergency teamwork performance: development of the Team Emergency Assessment Measure (TEAM). Resuscitation 81, pp. 446-452.

Crichton, M.T. 2001. Training for decision making during emergencies. Horizons of Psychology 10. 4, pp. 7-22.

Crichton, M.T. \& Flin, R. 2004. Identifying and training non-technical skills of nuclear emergency response teams. Annals of Nuclear Energy 31, pp. 1317-1330.

Crocq, L., Huberson, S. \& Vraie, B. 2009. Gérer les grandes crises sanitaires, économiques, politiques et économiques. Odile Jacob, 297 p.

Dautun, C. 2007. Contribution à l'étude des crises de grande ampleur: connaissance et aide à la décision pour la Sécurité Civile. Ecole Nationale Supérieure des Mines de Saint-Etienne, 407 p.

Dimock, H.G. \& Kass, R. 2010. Comment observer votre groupe. Captus Press, Canada, 105 p.

Dubiau, P. 2007. Gestion d'une urgence radiologique : organisation et fonctionnement. Techniques de l'ingénieur. Génie nucléaire, vol. BN4, n BN3870.

Entin, E.E. \& Entin, E.B. 2001. Measures for evaluation of team processes and performance in experiments and exercises. In proceedings of the $6^{\text {th }}$ International Command and Control Research and Technology Symposium. June 19-21 2001, Annapolis, Maryland, 14 p. 
Fanning, R.M. \& Gaba, D.M. 2007. The Role of Debriefing in Simulation-Based Learning. Society for Simulation in Healthcare vol.2, no. 2, 11p

Fowlkes, J.E. \& Burke, C.S. 2005. Event-Based Approach to Training (EBAT). In N. Stanton, A. Hedge, K. Brookhuis., E. Salas \& H. Hendrick (eds), Handbook of Human Factors and Ergonomics Methods. CRC Press, $681 \mathrm{p}$.

Fowlkes, J.E. \& Burke, C.S. 2005. Targeted Acceptable Responses to Generated Events and Acceptable Responses (TARGETs). In N. Stanton, A. Hedge, K. Brookhuis., E. Salas \& H. Hendrick (eds), Handbook of Human Factors and Ergonomics Methods. CRC Press, $681 \mathrm{p}$.

Fowlkes, J.E., Lane, N.E., Salas, E., Franz, T. and Oser, R. 1994. Improving the measurement of team performance : the TARGETs methodology. Military Psychology, 6(1), pp. 47-61.

Gaultier-Gaillard, S., Persin, M. \& Vraie, B. 2012. Gestion de crise: les exercices de simulation: de l'apprentissage à l'alerte. AFNOR, $219 \mathrm{p}$.

Heiderich, D. 2010. Plan de gestion de crise: organiser, gérer et communiquer en situation de crise. Editions Dunod, Paris, $256 \mathrm{p}$.

Helmreich, R.L. \& Foushee, H.C., 2010. Why CRM? Empirical and Theoretical Bases of Human Factors Training, pp.3-58. In B. Kanki, R. Helmreich \& J. Anca (eds), Crew Resource Management. Second edition, Academic Press, 512 p.

International Civil Aviation Organization, 2002. Line Operations Safety Audit (LOSA). Doc 9803 AN/761.

Kanki, B. 2010. Communication and Crew Resource Management, pp. 111-146. In B. Kanki, R. Helmreich \& J. Anca (eds), Crew Resource Management. Second edition, Academic Press, $512 \mathrm{p}$.

King, H.B., Battles, J., Baker, D.P., Alonso, A., Salas, E., Webster, J., Toomey, L. \& Salisbury, M. 2008. TeamSTEPPS: Team Strategies and Tools to Enhance Performance and Patient Safety, pp. 21-36. In K. Henriksen, J. Battles, M.A. Keyes \& M.L. Grady (eds), Advances in Patient Safety: New Directions and Alternative Approaches. AHRQ Publication no. 08-0034-3, $456 \mathrm{p}$.

Kontogiannis, T. \& Kossiavelou, Z. 1999. Stress and team performance : principles and challenges for intelligent decision aids. Safety Science, 33(3), pp. 103-128.

Kosarzycki, M.P., Salas, E., Wilson, K.A. \& DeRouin, R. 2002. Teamwork Training in Organizations: The Case of Training Resource Management. PSYKHE, vol.11, $\mathrm{n}^{\circ} 2$, pp. 121-140.

Kouabenan, D.R., Cadet, B., Hermand, D. \& Munoz Sastre, M.T. 2006. Psychologie du risque : identifier, évaluer, prévenir. Ouvertures psychologiques. 348 p.

Kowalski-Trakofler, K.M. \& Vaught, C. 2003. Judgement and decision making under stress: an overview for emergency managers. International Journal of Emergency Management.

Lachtar, D. 2012. Contribution de l'intelligence artificielle à l'analyse de la performance organisationnelle d'une cellule de crise communale. Institut des Sciences et Technologies Paris Tech, $269 \mathrm{p}$.

Lagadec, P. 1991. La gestion des crises - Outils de réflexion à l'usage des décideurs, McGraw-Hill, $300 \mathrm{p}$.

Lagadec, P. 2012. Du risque majeur aux mégachocs. Editions Préventique, 224 p.

Marks, M., Mathieu, J.E. \& Zaccaro, S.J. 2001. A temporally based framework and taxonomy of team processes.
Academy of Management Review, vol.26, no.3, pp. 356376.

Orasanu, J.M. 2010. Flight Crew Decision-Making, pp. 147-180. In B. Kanki, R. Helmreich \& J. Anca (eds), Crew Resource Management. Second edition, Academic Press, $512 \mathrm{p}$.

Pearson, C. \& Clair, J.A. 1998. Reframing crisis management. Academy of Management Review, 23 (1), pp. 5976.

Power, D., Henn, P., O’Driscoll, P., Power, T., McAdoo, J., Hynes, H. \& Cusack, S. 2013. An evaluation of high fidelity simulation training for paramedics in Ireland. International Paramedic Practice, vol.2, n ${ }^{\circ}$, pp. 11-18.

Rosen, M.A., Weaver, S.L., Lazzara, E.H., Salas, E., Wu, T., Silvestri, S., Schiebel, N., Almeida, S. \& King, H.B. 2010. Tools for evaluating team performance in simulation-based training. Journal of Emergencies Trauma and Shock (JETS), vol.3, pp.353-359.

Roux-Dufort, C. 2007. A passion for imperfections, pp.221252. In C. Pearson, C. Roux-Durfort \& J.A. Clair (eds), International handbook of organizational crisis management. Sage publications, Thousand Oaks, 354 p.

Salas, E. \& Cannon-Bowers, J.A. 2001. The Science of Training: A Decade of Progress. Annual Review of Psychology, vol. 52:471-499, 28 p.

Salas, E., Rosen, M.A., Held, J.D. \& Weissmuller, J.J. 2009. Performance measurement in Simulation-Based Training: A Review and Best Practices. SAGE, Simulation Gaming, 40;328, 50 p.

Sayegh, L., Anthony, W.P., \& Perrewé, P.L. 2004. Managerial decision-making under crisis: The role of emotion in an intuitive decision process. Human Resource Management Review 14, pp. 179-199.

Seppänen, H., Mäkelä, J., Luokkala, P. \& Virrantaus, K. 2013. Developing shared situational awareness for emergency management. Safety Science 55, pp. 1-9.

Shanahan, C., Best, C., Finch, M. \& Sutton, C. 2007. Measurement of the Behavioural, Cognitive, and Motivational Factors Underlying Team Performance. Air Operations Division, Defence Science and Technology Organisation, DSTO-RR-0328, Australie, 79 p.

Shapiro, M.J, Gardner, R., Godwin, S.A., Jay, G.D., Lindquist, D.G., Salisbury, M.L. \& Salas, E. 2008. Defining Team Performance for Simulation-based Training: Methodology, Metrics, and Opportunities for Emergency Medicine. Academic Emergency Medicine, 15:10881097.

Shinnick, M.A., Woo, M., Horwich, T.B. \& Steadman, R. 2011. Debriefing: The Most Important Component in Simulation? Clinical Simulation in Nursing 7, pp. 105111.

Tena-Chollet, F. 2012. Elaboration d'un environnement semi-virtuel de formation à la gestion stratégique de crise, basé sur la simulation multi-agents. Ecole Nationale Supérieure des Mines de Saint-Etienne, 394 p.

Thomas, E.J., Sexton, J.B. \& Helmreich, R.L. 2004. Translating teamwork behaviours from aviation to healthcare: development of behavioural markers for neonatal resuscitation. Qual Saf Health Care 13 (Suppl 1): i57-i64.

Vaughan, D. 1996. The Challenger Launch Decision: risky technology, Culture and Deviance at NASA. University of Chicago Press, Chicago and London, pp. 153-196.

Vliet, A.J. \& Amelsfoort, D., 2008. Multinational military teams. NATO Science and Technology Organization, $16 \mathrm{p}$.

Weick, K.E. 1995. Sensemaking in organizations, Foundations for Organizational Science, 248 p. 